\title{
Hepatitis B virus (HBV) immunoglobulin effect on HBV and hepatitis D virus reactivation after liver transplantation
}

\author{
Anar Ganbold, Munkhtsetseg Chimedtseren, Odontungalag Norov, Sumiya Bayarsaikhan, Bayarmaa Ochirkhuree
}

Department of Gastroenterology, First Central Hospital of Mongolia, Ulaanbaatar, Mongolia

Background: Post-liver transplantation (LT) use of hepatitis B virus immunoglobulin (HBlg) is still debated in the era of highly effective nucleos(t)ide analogues. This study aims to compare presence of hepatitis B virus surface antigen (HBsAg) and HBVDNA/HDV-RNA replications post-LT, depending on HBIg administration.

Methods: We divided patients into $125 \mathrm{HBV}$ and $57 \mathrm{HBV} / \mathrm{HDV}$-cohorts. They were operated in various centers around the world before April 1, 2018 into HBIg and non-HBIg groups. In the HBV-cohort, the HBIg-group had 31 patients, non-HBlg-group had 76 patients. Eighteen patients were not sure of their HBIg status. All patients were taking either entecavir, tenofovir alafenamide or tenofovir fumarate on a continuous basis. Any patient that suffered viral reactivation due to non-compliance was removed from analysis. The data was processed in GraphPad, Prism (GraphPad, San Diego, CA, USA).

Results: In the HBIg-group, HBsAg was tested in 20 patients and detected in three (15\%), while HBV-DNA tested in 15 and was positive in two (13.33\%). In non-HBlg-group, HBsAg was tested in 42 and detected in nine (21.42\%), HBV-DNA was tested in 52 and detected in eight (15.38\%). In HBV/HDV-cohort, 14 patients received HBIg and one (20\%) had HDV-RNA replication out of five tested. Non-HBIg group had 34 patients, out of 18 tested six (33\%) had HDV-RNA replication.

Conclusions: It appears that the HBsAg is found in $15 \%-21 \%$ patients post-LT. We found no statistically significant difference between HBIg and non-HBlg groups in terms of HBsAg positivity, HBV-DNA $(P=0.37)$ and HDV-RNA $(P=0.22)$ replications. This was especially true for HBV replication. However, we cannot rule out usefulness of HBlg therapy in terms of HDV replication, where number of PCRs performed were low in both HBIg and non-HBlg groups. Limiting factors were the absence of pre-LT viral load information and lack of standardized viral replication tests for this study.

Corresponding author: Anar Ganbold

E-mail: g.anar@fchm.edu.mn

(c) The Korean Society for Transplantation

This is an Open Access article distributed under the terms of the Creative Commons Attribution Non-Commercial License (http://creativecommons.org/licenses/by-nc/4.0/) which permits unrestricted non-commercial use, distribution, and reproduction in any medium, provided the original work is properly cited. 